\title{
Prevenção de conflitos médico-legais no exercício da medicina
}

\section{Prevention of medico-legal conflicts in medical practice}

\author{
José Guilherme MinossI, TCBC-SP1
}

\author{
RE S U M O
}

\begin{abstract}
Os conflitos médico-legais que ocorrem no exercício da Cirurgia e da Medicina são motivos de preocupação não só no meio médico, mas também na sociedade como um todo, pois se de um lado geram um maior desgaste emocional ao médico, por outro, os pacientes estão sendo rejeitados. As causas desses conflitos são muitas, envolvendo fatores não assistenciais, como o sistema de saúde distorcido e desorganizado, a falta de participação da sociedade e do médico na melhoria desse sistema, o aparelho formador que lança no mercado grande número de jovens médicos despreparados para o exercício dessa nobre profissão, além da falta do ensino continuado. A solução para esses conflitos não poderá ser por meio de simples criação de leis, e nem pela negativa da existência do erro médico, que ocorre numa freqüência até maior do que os próprios conflitos. Todavia, pode-se afirmar que é muito importante melhorar a relação médico-paciente. É necessário, ainda, que o médico conheça a fundo seus deveres de conduta e que, principalmente, se abstenha de praticar abusos do poder. A sociedade deve também entender que a saúde não é uma questão exclusiva dos médicos e que deve lutar pela melhoria das condições dos níveis de vida.
\end{abstract}

Descritores: Erros Médicos. Cirurgia. Ética médica. Responsabilidade legal.

\section{INTRODUÇÃO}

$\mathrm{N}^{\mathrm{a}}$ ão existem estatísticas oficiais sobre a totalidade de processos por erro médico no Brasil. Há, sim, levantamentos gerais e avaliações pessoais, ou impressões sobre o aumento progressivo das ações judiciais contra médicos. Todavia, essa crescente tendência ainda não é considerada abusiva em nosso meio. Nossa pletora de demandas considera-se perfeitamente no perfil de um país em desenvolvimento. É fato que em países desenvolvidos tais eventos são muito mais significativos. Isto, porém, não significa que nos mesmos o número de erros médicos seja maior. No Brasil, ainda que sem dados oficiais, nossas estatísticas estão abaixo das observadas em países desenvolvidos, mas, acima dos menos desenvolvidos ${ }^{1}$.

O número de causas judiciais por erro médico, no entanto, vem aumentando no Brasil, não se podendo afastar que em breve tenhamos uma realidade completamente diferente da observada hoje.

O erro presumido é uma das acusações mais freqüentes nas ações judiciais. Os doentes também incluem a falta de consentimento para que o médico realize as intervenções, mesmo quando a operação se apresenta dentro das exigências técnicas e legais².

Na prática, vem se imputando ao médico uma grande variedade de erros profissionais, tais como: exame superficial do paciente, realização de operações desnecessárias, omissão de tratamentos, retardamento na transfe- rência para outro especialista, descuidos na realização de transfusões de sangue ou de anestesias, prescrições erradas, abandono do paciente, negligência no pós-operatório, omissão de instrução necessária aos pacientes, dentre outras.

Um aspecto importante que pode ter influenciado no aumento dos conflitos é a mudança do relacionamento entre o médico e o paciente. O laço paternal que existia entre as famílias e os médicos de cabeceira transformou-se pouco a pouco numa relação quase impessoal. Por outro lado, a especialização tem transformado o médico num técnico altamente adestrado e impessoal, que cada vez mais tem dificuldade de conciliar os conhecimentos milenares da Medicina tradicional, com os enormes avanços tecnológicos e instrumentais da Medicina moderna².

A Medicina antiga, inibida e solitária, era incapaz de grandes feitos, portanto gerava poucos riscos e consequentemente, era menos danosa. Nos tempos atuais, em que a ciência médica apresenta grande arsenal tecnológico, beneficiando em muito o ser humano, tornouse mais invasiva, com maiores riscos e danos ao paciente.

Sendo assim, os efeitos danosos verificados durante o exercício da Medicina, não podem mais ser atribuídos somente ao binômio médico-paciente, e sim, à coletividade como um todo, já que é também beneficiária desse avanço. Assim, seriam ações justas que a coletividade também procurasse ajudar a encontrar uma solução de reparar civilmente o dano, de maneira mais imediata, menos

Trabalho realizado no Departamento de Cirurgia e Ortopedia da Faculdade de Medicina de Botucatu - Unesp, SP, BR

1. Professor Assistente Doutor do Departamento de Cirurgia e Ortopedia da Faculdade de Medicina de Botucatu - Unesp; Perito Judicial, SP, BR. 
confrontante com o médico, assegurando maior tranqüilidade ao exercício profissional. Seria a chamada socialização do risco médico, que certamente atenderia melhor à justiça coletiva.

Esse fato é muito importante, pois, com o aumento do número de pressupostos erros médicos no Brasil, tem se observado uma situação inusitada, que é a consolidação da medicina defensiva, onde o médico facultativo na tentativa de se proteger, exagera no pedido de exames subsidiários mais sofisticados, se omite nos procedimentos de alto risco e, por vezes, recusa pacientes graves, com doenças complexas e com maior potencial de complicações ou seqüelas.

Essa posição defensiva, além de se constituir em um fator de diminuição da assistência aos pacientes de maior risco, leva a um maior custo da medicina, não só para o usuário, como para a sociedade como um todo.

\section{ASPECTOS JURÍDICOS DA RESPONSABILIDADE MÉDICA}

Encontra-se na culpa o fundamento jurídico da responsabilidade médica. Procede culposamente quem age sem o necessário cuidado e julga que o resultado não se dará. É necessário que o agente tenha dado causa sem ter requerido o resultado, mas que o tenha feito por negligência, imprudência ou imperícia².

A negligência caracteriza-se pela inação, indolência, inércia, passividade. É a falta de observância aos deveres que as circunstâncias exigem. É um ato omissivo.

Imprudente é o médico que age sem a cautela necessária. A conduta é caracterizada pela intempestividade, precipitação, insensatez. A imprudência tem sempre caráter comissivo, isto é, resulta de uma atuação e não de omissão.

Imperícia é a falta de observação às normas, por despreparo prático ou por insuficiência de conhecimentos técnicos.

Na efetivação da responsabilidade médica, alguns quesitos são indispensáveis.

O autor - É necessário que o profissional esteja habilitado legalmente para o exercício da medicina, caso contrário, além de responsabilizado, será punido por exercício ilegal da medicina, curanderismo ou charlatanismo.

O ato - Deverá ser o resultado danoso de um ato lícito, pois, do contrário, tratar-se-á de uma inflação delituosa mais grave, como por exemplo, o aborto criminoso ou a eutanásia.

A culpa - Consiste na ausência do dolo, ou seja, que o autor tenha produzido o dano sem a intenção de prejudicar, mas o tenha feito por: negligência, imprudência ou imperícia.

O dano - Sem a existência de um dano real, efetivo e concreto, não existe responsabilidade.

O nexo causal - É a relação entre causa e efeito, um elo entre o ato e o dano.
É nessa dimensão que deve considerar-se o significado de erro médico.

O erro médico, quase sempre por culpa, é uma forma de conduta profissional inadequada, que supõe uma inobservância técnica, capaz de produzir um dano à vida ou à saúde do paciente. É o dano sofrido pelo paciente que possa ser caracterizado como imperícia, negligência ou imprudência do médico, no exercício de suas atividades profissionais.

É importante, no entanto, distinguir o erro médico de acidente imprevisível e de resultado incontrolável.

No acidente imprevisível, há um resultado lesivo, supostamente oriundo de caso fortuito ou força maior, à integridade física ou psíquica do paciente durante o ato médico. Seria, por exemplo, o caso de um cirurgião que vai executar uma colecistectomia, e lesa inadvertidamente o colédoco, promovendo posteriormente danos ao paciente. Se o cirurgião devidamente habilitado realizou o ato com toda cautela e teve um mau resultado, obviamente não poderá responder pelo dano, pois não se trata de erro médico e sim, um acidente imprevisível.

O resultado incontrolável seria aquele decorrente de uma situação grave e de curso inexorável. Ou seja, aquele resultado danoso proveniente de sua própria evolução, para o qual as condições atuais da ciência e a capacidade profissional ainda não oferecem solução.

Por isso, o médico tem para com o paciente uma "obrigação de meios" e não de "resultados". Ele assume um compromisso de prestar meios adequados, de agir com diligência e de usar seus conhecimentos na busca de um êxito favorável, o qual nem sempre é certo.

O erro médico pode ser argüido sob duas formas de responsabilidade: a legal e a moral. A responsabilidade moral é da competência dos Conselhos de Medicina, através de processos ético-disciplinares.

A responsabilidade legal é atribuída pelos tribunais, podendo comportar, entre outras, as ações penais e civis.

A responsabilidade penal do médico é regulada principalmente pelo Código Penal, que está em vigor desde 1940, mas teve a parte geral reformada pela Lei $n^{\circ}$ 7.209/84, além de outras leis específicas como a Lei dos Juizados Especiais Civis e Penais, a Lei n 9.099/95.

Não é comum nos processos de erro médico, que o mesmo seja processado criminalmente, e sim civilmente, pois o que se deseja é, de um modo geral, a reparação financeira do dano.

Atualmente, no Brasil, a responsabilidade civil por erro médico é disciplinada pelo Código de Defesa do Consumidor e pelo novo Código Civil, que dispõem sobre a natureza da responsabilidade do profissional e dos prestadores de serviço de saúde, as modalidades de indenização cabíveis, o ônus da prova, entre outros aspectos. A legislação aplicável é relativamente recente, já que a vigência do Código de Defesa do Consumidor data de 11 de março de 1991, e a do novo Código Civil, de 11 de janeiro de $2003^{3}$. 
A responsabilidade civil gira em torno de duas teorias: a subjetiva e a objetiva ${ }^{4}$.

A teoria subjetiva tem na culpa seu fundamento basilar. Argüi-se a responsabilidade do autor quando existe culpa, o dano e o nexo causal.

Na teoria objetiva da responsabilidade, que tem no risco sua viga mestra, o responsável pelo dano indenizará simplesmente por existir um prejuízo, não se cogitando da existência de sua culpabilidade, bastando a causalidade entre o ato e o dano, para obrigar a reparação.

Atualmente, mesmo com as mudanças ocorridas no Código de Defesa do Consumidor e no novo Código Civil, em relação ao regime de responsabilidade civil, os médicos (e demais profissionais liberais), respondem, perante o paciente, somente mediante a comprovação de sua culpa (negligência, imprudência ou imperícia).

Ressalta-se que os estabelecimentos de saúde respondem, de um modo geral, objetivamente pelos danos causados aos seus usuários. Fato semelhante ocorre na cirurgia plástica, onde os tribunais com freqüência aplicam a teoria objetiva na cirurgia embelezadora, alegando que nesses casos configura obrigação de resultados e não de meios.

\section{DEVERES DE CONDUTA DO MÉDICO}

Qualquer que seja a forma de avaliar a responsabilidade de um profissional em determinado ato médico, no âmbito ético ou legal, é imprescindível que se levem em conta seus deveres de conduta.

\section{Dever de informação}

É fundamental que o paciente seja informado pelo médico sobre a necessidade de determinadas condutas ou intervenções e sobre seus riscos e conseqüências. No caso de menores ou incapazes, essas informações devem ser fornecidas aos pais ou representante legal.

É necessário que todas as informações sejam registradas no prontuário, que é uma das primeiras fontes de consulta e informação sobre um procedimento médico contestado.

\section{Dever de atualização}

O regular exercício profissional do médico não requer apenas uma habilitação legal. Implica também no aprimoramento continuado, adquirido por meio dos conhecimentos mais recentes da nossa profissão. A capacitação profissional é sempre verificada toda vez que se discute uma responsabilidade médica. Além disso, o artigo 5, do Código de Ética Médica, diz que: "o médico deve aprimorar continuamente seus conhecimentos e usar o melhor do progresso científico em benefício do paciente".

\section{Dever de vigilância}

$O$ ato médico deve estar isento de qualquer tipo de omissão que possa ser caracterizado por inércia, passividade ou descaso. Essa omissão tanto pode ser por abandono do paciente, como por restrição do tratamento ou retardo no encaminhamento necessário.

Enquadra-se nessa situação, a troca de medicamento por letra indecifrável, o esquecimento de corpo estranho em operações, medicar por telefone, transfusões incompatíveis, dentre outras.

\section{Dever de abstenção de abuso}

Quando da avaliação do dano produzido por um ato médico, deve ficar claro, entre outros, se o profissional agiu com a cautela devida e, portanto, descaracterizado de precipitação, inoportunismo ou insensatez.

Exceder-se na terapêutica ou nos meios propedêuticos mais arriscados é uma forma de desvio de poder e, se o dano deveu-se a isso, não há como negar a responsabilidade. Ainda que esses meios não sejam invasivos ou de grande porte, basta ficar patente a sua desnecessidade.

Sendo assim, usar abusivamente meios diagnósticos invasivos ou não, indicar operações desnecessárias, realizar experiências no ser humano, fora de protocolos de estudo e sem o devido consentimento, são algumas formas de abuso que por vezes terminam em dano ao paciente e, portanto, são passíveis de condenação do médico.

\section{PREVENÇÃO DO RISCO DE ERRO MÉDICO}

Os aspectos médicos legais que regem, hoje, o exercício da Medicina e da Cirurgia, devem ser de conhecimento do médico, com certa profundidade. Deve iniciar precocemente em sua formação, talvez quando ainda estudante, e sofrer uma contínua atualização, semelhante aos conhecimentos necessários para acompanhar a evolução da ciência, que é extremamente dinâmica.

Temos observado que cada vez mais os médicos se preocupam com a possibilidade de terem que enfrentar os tribunais, mas que na maioria das vezes, conhecem pouco sobre o assunto.

Uma maneira objetiva de tentar prevenir-se de cometer erros no exercício da Medicina, seria conhecer os fatores de risco.

Na prática, são muitos os fatores de risco que levam ao mau resultado. São classificados didaticamente em assistenciais e não assistenciais, conforme estejam relacionados direta ou indiretamente à assistência.

Entre os fatores não assistenciais, destacam-se:

\section{1) O Sistema de Saúde}

O Sistema de Saúde Pública é distorcido e desorganizado. Temos uma rede básica de saúde que funciona mal, é desestruturada na maioria dos municípios brasilei- 
ros, onde existem profissionais mal remunerados, com limitação de sua atuação. Conseqüentemente, a população não consegue ter uma resolubilidade adequada dos problemas que a afligem.

A rede hospitalar de quase todo país, onde deveria exercer-se a Medicina curativa e de urgência, está cada vez mais sucateada, haja vista os insuficientes investimentos tanto pelo poder público municipal e estadual, bem como federal. Todavia, existem ilhas de serviços públicos eficientes, normalmente concentrados em grandes hospitais públicos ou fundações, ou em centros universitários de excelência, que freqüentemente executam procedimentos de alta complexidade.

Por outro lado, a criação das empresas de assistência médica, que prioritariamente visam o lucro, além de remunerarem mal os profissionais da saúde, com freqüência limitam a sua atuação, o que coloca entre o médico e o paciente muitos conflitos, os quais quase sempre levam à complexas implicações de ordem ética e legal.

Portanto, o médico exerce suas atividades em um ambiente de penúria e precariedade.

\section{2) A falta de compromisso do médico}

O médico deve trabalhar sempre em condições próximas às ideais, devendo denunciar as condições inadequadas de trabalho, não ficando indiferente como tem acontecido, pois o exercício da Medicina é um ato político em favor da saúde individual e coletiva, e também a busca da cidadania. Portanto, é dever do médico lutar organizadamente em favor das melhores condições de atendimento e não considerar a doença como um resultado da fatalidade.

\section{3) A não participação da sociedade}

A sociedade, por intermédio dos seus movimentos organizados, deve entender que a luta contra o mau resultado na assistência médica passa por propostas e encaminhamentos das políticas sociais, públicas e que esse resultado indesejável não tem como única causa os erros dos médicos. Sendo assim, o ideal seria que esses grupos se aliassem aos médicos e a todos aqueles que se interessam pela luta em favor da boa assistência médica, no sentido de exigir, principalmente de órgãos governamentais, uma melhoria nas condições de vida e saúde da população.

\section{4) A não-revisão do aparelho formador}

O Brasil é o país que tem o maior número de escolas médicas do mundo, com Cursos de Graduação, de um modo geral, deficitários, sendo que quase $50 \%$ dos formandos não têm acesso a uma Residência Médica ou a um curso de especialização.

Além das péssimas condições de ensino e aprendizagem, temos os baixos salários dos professores e o aparelho formador não lança no mercado médico com o perfil adequado para as exigências da sociedade. Sem falar, ainda, na falta de recursos para a pesquisa e a extensão.
Seria necessária uma revisão sobre a qualidade de ensino, e também dos critérios adotados para abertura de novos cursos de Medicina.

\section{5) A falta de ensino continuado}

É evidente que para se exercer-se a profissão médica não basta apenas uma habilitação legal, representada pela posse de um diploma e seu registro nos Conselhos de Medicina. É necessária uma contínua habilitação profissional constituída de um permanente aprendizado, que pode ser adquirido por meio da leitura das publicações especializadas, participação em congressos, curso de especialização ou estágios em centros hospitalares de referência.

Com relação aos fatores assistenciais podemos

citar:

\section{1) O desgaste da relação médico-paciente}

Uma relação médico-paciente amistosa deixa o assistente e 0 assistido em condições de exercer com tranqüilidade seus papéis. Todavia, o que se observa é um desgaste dessa relação, por inúmeros motivos, dentre os quais: o pequeno tempo que o médico tem-se dedicado a conversar com o paciente, principalmente por ser mal remunerado, por ter vários empregos e também pelo uso excessivo da tecnologia em detrimento da Medicina tradicional, baseada na observação, na história, na percepção da doença e do doente. Deve o médico arrumar uma fórmula de dedicar maior tempo ao contato com o paciente, orientando-o de forma mais carinhosa e explicando-lhe sobre todos os procedimentos a serem realizados, com seus riscos e conseqüências. Mesma conduta deve ter em relação aos familiares, pois um relacionamento mais pessoal com o assistido e seus próximos, pode evitar muitos conflitos legais.

\section{2) A falta das condições de trabalho}

Não há nenhuma dúvida de que boa parte dos danos produzidos no exercício da Medicina, deve-se às péssimas condições de trabalho dos médicos. Mais fácil, porém, é culpar os mesmos como os primeiros responsáveis. Pouco pode ser feito pelo profissional isoladamente, que na maioria das vezes, não tem outra opção, a não ser se submeter-se a condições precárias e humilhantes do seu dia a dia de trabalho. Nossas entidades de classe, inexplicavelmente, têm tido pouco poder de denunciar e de tentar resolver junto aos órgãos municipais, estaduais e federais essas graves falhas estruturais de nosso sistema de saúde.

\section{3) $O$ abuso de poder}

Abusa do poder o médico que atua sem a devida cautela, isto é, de maneira precipitada, inoportuna ou insensata. Uma forma comum de desvio do poder é o médico que executa procedimentos sem ter a devida qualificação. Isso não significa que o médico deva exercer exclusivamente sua especialidade. Pode e deve atuar em diversas áreas da Medicina, sempre em benefício do paciente, mas essa atuação deve ser prudente, diligente e com perícia. 
Outra forma condenável e, por isso, agravante numa avaliação por suposto erro é o procedimento desnecessário. Temos observado na prática clínica diária um uso abusivo e cada vez maior de procedimentos diagnósticos, muitas vezes invasivos utilizados sem uma boa indicação. Pior, procedimentos cirúrgicos desnecessários têm sido muito freqüentes. Podemos citar, hoje, o uso abusivo de operações para tratamento de doença por refluxo gastroesofágico, mesmo havendo um consenso nacional que rege o tratamento dessa afecção. O mesmo acontece com a cirurgia bariátrica, que também tem sido indicada indiscriminadamente. É também comum histerectomias desnecessárias, operações de cistos foliculares do ovário, dentre outras.

O abuso de poder por parte do médico é o único item que depende exclusivamente da atuação do mesmo e pelo fato de sempre expor o doente a um risco desnecessário, constitui-se numa conduta odiosa e que deve ser duramente combatida.

\section{4) A falsa garantia de resultado}

O médico, embora deva ser sempre otimista quando se relaciona com o paciente, ele não deve garantir resultados, pois caso o faça, ele está assumindo uma obrigação de obtê-lo e não uma obrigação de meios. Deve evitar, também, minimizar um procedimento, como por exemplo, na cirurgia laparoscópica, em que alguns profissionais se comprometem a realizar a intervenção por "furinhos" ou a "laser", como é chamada popularmente a cirurgia por laparoscopia. Caso o resultado não seja obtido, passa a ser uma violação ao dever de informar devida e corretamente.

\section{5) A falta do consentimento esclarecido}

Trata-se de documento assinado pelo paciente ou responsável, consentindo ao médico a realização de determinado procedimento diagnóstico ou terapêutico, após haver recebido informações indispensáveis sobre a sua execução. Tem como finalidade garantir a autonomia de vontade do paciente e delimitar a responsabilidade do médico que realiza o procedimento, uma vez que dessa forma cumpre com o seu dever de bem informar.

O consentimento deve ser obtido de um indivíduo civilmente capaz, isento de coação, influência ou indução, por meio de linguagem acessível ao seu nível de convencimento e compreensão. O consentimento não é um ato irretratável e permanente, portanto, deve obedecer princípios da revogabilidade e da temporalidade ${ }^{2}$.

O termo de consentimento esclarecido deve ser encarado como uma peça para a defesa do médico, não se constituindo, todavia, em prova absoluta, pois apenas integra, na qualidade de prova documental, o arsenal probatório a ser apresentado ao juízo.

Por outro lado, deve ficar claro que o fato de se ter um consentimento esclarecido, isto, por si só, não isen- ta o médico quando da existência de outras faltas no cumprimento dos deverem de conduta.

\section{6) O preenchimento inadequado de prontuários}

Um dos elementos mais valorizados quando da avaliação de um procedimento médico contestado é o prontuário do paciente.

O prontuário deve ser minucioso, estar de forma legível, ordenado e conciso. Deve conter o exame clínico, prescrição, relatórios de enfermagem, os relatórios de anestesia, operação, a ficha de registro de resultados de exames complementares, além da ficha de controle de infecção e resumo de alta.

Apesar da importância deste documento, temse observado nos casos de perícias judiciais, que muitas vezes o mesmo é incompleto, com letra ilegível, com dados conflitantes com a enfermagem, quando eventualmente ausente.

\section{7) $O$ abandono do paciente}

A regra é que o médico não pode abandonar seu paciente, a não ser em situações muito especiais, previstas no artigo 61 do Código de Ética Médica, já que existe entre o médico e o paciente uma relação contratual.

Falta com o dever de vigilância em casos de operação o médico que negligencia algumas complicações pósoperatórias, como por exemplo os cuidados com a hidratação, o diagnóstico precoce de deiscência de suturas, infecções, etc, que normalmente requerem uma conduta imediata.

\section{COMO PROCEDER DIANTE DA ALEGAÇÃO DE ERRO MÉDICO}

Se aberto o processo judicial, mesmo que seu andamento seja demorado, não deve ser negligenciado pelo médico, que precisa, inclusive, aproveitar o momento para conhecer melhor os aspectos médicos-legais que regem exercício da Medicina e particularmente da Cirurgia. Deve saber que os juízes têm sido cuidadosos em analisar os processos, tendo absoluto conhecimento sobre a falibilidade da ciência médica e as condições adversas em que o médico trabalha em nosso país. Têm sido também criteriosos no estabelecimento de indenizações tanto pecuniárias como por danos morais, ao contrário do que ocorre nos EUA, em que o valor excessivo das indenizações tem levado a uma Medicina defensiva, onde recusa-se paciente e evita-se procedimentos de alto risco.

O médico não deve ainda considerar a existência de uma alegação de má prática como sinônimo de incompetência profissional, nem deve considerar o processo uma coisa sem importância, devendo sempre constituir um procurador legal. Deve também nomear um assistente técnico, que é um médico da parte e que irá acompanhar a atuação do perito oficial. $O$ assistente técnico deve sempre que possível ter conhecimento específico da matéria em 
questão e também poderá elaborar um parecer que será apreciado pelo magistrado.

À semelhança do que ocorre em outros países, as partes poderão fazer um acordo fora do tribunal, que normalmente evita maiores prejuízos emocionais ou financeiros e risco de condenação no julgamento. Todavia, essa é uma conduta muito pessoal e deve ser analisada caso a caso e sempre com a orientação de um procurador jurídico.

\section{Agradecimento}

Ao Professor Adjunto César Tadeu Spadella pela revisão do texto e valiosas sugestões.

\title{
A
}

\begin{abstract}
Generally, medico-legal conflicts which occur in surgical and medical practice are a source of worry for both the medical profession and the society as a whole, because on one hand, they could cause high emotional stress for doctors, and on the other hand, patients could be rejected. Once consolidated, defensive medicine increases treatment costs and the doctor-patient relationship could transform into a tragedy. There are many causes for this, including non-treatment factors, such as an unsupported and disorganized health system, lack of participation from society and the doctor in improving this system, the training machine which launches a large number of young unprepared doctors to practice in this noble profession, along with a lack of continuing training, as there are few public or private institutions providing preparation, or further medical training. The related treatment factors are generally, a deficient doctor-patient relationship, poor work condition, power abuse by the doctor, a lack of clear agreement, and poor medical record keeping. These conflicts cannot be solved by simple creating legislation, or by denying the existence of medical error, which occurs at higher frequency than the actual conflicts. It is very important to improve the doctor-patient relationship because an effective fraternal relationship reduces the chance of a judicial demand. The doctor still needs to fully understand his/her conduct obligations and mainly to avoid power abuse. Doctors must also professionally link themselves with politicians who fight for the individual's rights against the system. Society must also understand that health is not just an issue exclusive for doctors, and people must fight to improve living conditions. Society must seriously show its frustration with the increasing disparity between scientific possibilities and actual wellbeing. The training machine needs immediate profound changes to produce professionals with the highest qualifications equipped for the needs of our population.
\end{abstract}

Key words: Medical errors. Surgery. Ethics. Medical. Liability legal.

\section{REFERENCIAS}

1. Veloso de França G. Direito Médico 8a ed. São Paulo: BYK; 2003

2. Minossi JG, Silva AL. Aspectos médico-legais da cirurgia para hérnia inguinal. Rev Col Bras Cir. 2005; 32(4): 214-7.

3. Mansur N, Ayer de Oliveira R. O médico e a justiça. Conselho Regional de Medicina do Estado de São Paulo; 2006.

4. Pimenta Jr JLB, Mendes BM. Parecer sobre Termo de Consentimento Informado. Boletim Sobed - RJ. 2004/05, nº 70, p. 5.

Recebido em 25/07/2008

Aceito para publicação em 18/09/2008

Conflito de interesse: nenhum

Fonte de financiamento: nenhuma

\section{Como citar este artigo:}

Minossi JG. Prevenção de conflitos médico-legais no exercício da medicina. Rev Col Bras Cir. [periódico na Internet] 2008; 35(5). Disponível em URL: http://www.scielo.br/rcbc

\section{Endereço para correspondência:}

José Guilherme Minossi

E-mail: jminossi@uol.com.br ou jminossi@fmb.unesp.br 